\title{
Comparison on the Effectiveness of Modular Learning in General Mathematics among the Senior High School Strands
}

\author{
Imee Borinaga-Gutierrez \\ Valencia National High School Ormoc City, Leyte, Philippines \\ imee.borinaga029@deped.gov.ph
}

\begin{abstract}
This study aimed to compare the effectiveness of modular learning among senior high school strands and investigate the influence of students' demographic profiles on their academic performances. Using One Way ANOVA, results showed a significant difference in the test scores obtained from the different strands. Results with Tukey HSD revealed that ABM performed best under modular learning, followed by STEM, GAS, ATS, and EIM, respectively. Pearson's $r$ revealed a significant correlation between student's sex, monthly income, and parents' employment status to students' academic performance. Furthermore, the $\mathrm{z}$ test for two means determined that there was a significant difference in the scores of males and females. From these results, the researcher suggests that teachers handling TVL tracks must exert extra effort in delivering their mathematics lessons to close the gap in academic performance with the students from academic tracks.
\end{abstract}

Keywords: Modular, General Mathematics, Strands, Senior High School, Academic Performance

\section{Introduction}

The Philippines education system has implemented the use of modules for instruction along with other modalities such as online learning, use of radio, television, and blended learning. $39.6 \%$ or 8.8 million students who answered DepEd's National Learner Enrolment and Survey Forms (LESFs) prefer modular learning over other modalities (Manlangit, 2020). Modular distance learning is a form of instruction which makes use of self-learning materials such as modules, textbooks, hand-outs, or learning activity sheets presented in digital or printed form. In this form of instruction, teachers deliver lesson content without facing the students personally. Parents, guardians, or para teachers act as More Knowledgeable Ones (MKOs) helping the student learn in the comfort of their home. This means that MKOs will have to guide the flow of instruction while teachers teac the lesson content. Learning materials will be received by students through email, messenger, CD/DVD, USB storage, designated stations set by each school, or delivery by teachers. In modular learning, teachers monitor students' progress through email, messenger, text message, call, or home visitation. Generally, it implies self-directed learning. While this means difficulty in teaching various subjects, there is no more significant challenge than teaching mathematics. The Republic of the Philippines ranks lower than the other countries in terms of mathematics. The Philippines joined the Programme for International Student Assessment (PISA) of the Organization for Economic Co-operation and Development (OECD) in the year 2018. This is a step undertaken to increase the quality of the Philippines basic education. As discussed in the PISA 2018 Philippine National Report, Filipino students achieved an average of 353 points, which is lower than the 489 points OECD average in Mathematical Literacy and is classified as below Level 1 proficiency (DepEd, 2019). 
Delivery of lesson content in Mathematics poses a challenge, not just to primary or junior high school teachers, but also to the senior high school teachers.

The Philippine Senior High School offers four (4) tracks for students to choose from Academic, Technical Vocational Livelihood (TVL), Arts \& Design, and Sports. There are four (4) strands under the academic track, which include Science, Technology, Engineering \& Mathematics (STEM), Accountancy \& Business Management (ABM), General Academic Strand (GAS), and Humanities \& Social Sciences (HUMSS). Under the TVL track, there are four (4) strands including, Information and Communication Technology, Home Economics, Industrial Arts and Agri-Fishery Arts (Senior High School in the Philippines: Curriculum Breakdown). Valencia National High School offers Automotive Servicing (ATS) and Electrical, Installation, and Maintenance (EIM) for this track. General Mathematics is one of the core subjects in senior high school, which means that every strand shall take this subject. The first quarter involves topics on the key concepts of functions, key concepts of rational functions, and key concepts of an inverse function. By this, the modular learning efficacy among the SHS strands is measured through their academic performance in the subject. The operational definition of academic performance used in this study is the students' test scores for the summative test covering the first quarter topics. Modular teaching in General Mathematics poses a question on its effectiveness as implemented in the different strands of Senior High School. With this, the researchers find the need to determine if there is a significant difference in the students' test scores in the different strands with the use of modular instruction. The influence of students' demographic profiles on their academic performance is another concern that needs to be addressed.

\section{Methods}

The study was conducted at Valencia National High School, located at Brgy. Valencia, Ormoc City, Leyte, the Philippines. The respondents for the study were the 213 Grade 11 students at Valencia National High School comprising the five strands offered in the school, namely Science, Technology, Engineering \& Mathematics (STEM), Accountancy \& Business Management (ABM), General Academic Strand (GAS), Automotive Servicing (ATS), and Electrical, Installation, and Maintenance (EIM). In calculating the sample size, Slovin's formula was used with a confidence level of 95\%. After determining the number of needed respondents for the study, stratified random sampling was used to highlight the differences in the academic performance between the strands, which will be a relevant result in comparing the effectiveness of modular learning. The number of respondents in each stratum was determined and was drawn randomly for the researchers to identify the respondents belonging to each stratum. This enables the researcher to be free from bias and obtain a sample population from the entire population, ensuring that each subgroup is well represented. A structured survey was carried out for this study. It comprised of two parts: personal information and questions about the respondents' demographic profile. Following was the 30-item multiple-choice test about the first quarter topics in General Mathematics. Data gathered was presented using a table and percentage to highlight the demographic profile of students in the different strands. One way Analysis of Variance (ANOVA) was used to determine a significant difference between students' test scores in the other various strands. Tukey HSD followed this to decide which strands have differed significantly. Pearson's correlation was then used to determine a 
correlation between students' academic performance and their demographic profile. Students drawn randomly from each stratum were classified as male or female and determine if this has a significant difference with their academic performance. The $\mathrm{Z}$ test for two means was used to determine if there is a significant difference between the scores of males and females under modular learning. Pearson Product Moment Correlation was used to test the validity of the test questions used. Cronbach's alpha was used in evaluating the consistency of the instrument. Kolmogorov-Smirnov test was used to determine the normality of the data. Levene's test was used to test the equality of variances. From the data gathered, the researchers generated necessary conclusions and recommendations for the study.

\section{Results and Discussion}

Table 1 shows that there is a greater number of females than the number of male respondents.

Table 1

Number of Male and Female Respondents

\begin{tabular}{ccc}
\hline Sex & Frequency & Valid Percent \\
\hline Female & 107 & 50.2 \\
Male & 106 & 49.8 \\
\hline Total & 213 & 100.0 \\
\hline
\end{tabular}

Table 2

\section{Monthly Income of Parents}

\begin{tabular}{lcc}
\hline \multicolumn{1}{c}{ Classifications } & Frequency & Valid Percent \\
\hline Poor (Below PHP 10,481) & 175 & 82.2 \\
Low income class (PHP 10,481 - PHP 20,962) & 30 & 14.1 \\
$\begin{array}{l}\text { Lower middle-income class (PHP 20,962 - PHP } \\
\text { 41,924) }\end{array}$ & 6 & 2.8 \\
Middle income class (PHP 41,924 - PHP 73,367) & 2 & .9 \\
$\begin{array}{l}\text { Upper middle-income class (PHP 73,367 - PHP } \\
\text { 125,772) }\end{array}$ & 0 & 0 \\
$\begin{array}{l}\text { Upper income class (PHP 125,772 - PHP } \\
\text { 209,620) }\end{array}$ & 0 & 0 \\
$\begin{array}{l}\text { Rich (PHP 209,620 and above) } \\
\quad \text { Total }\end{array}$ & 0 & 0 \\
\hline
\end{tabular}

Note. Adapted from the Philippine Institute for Development Studies

The majority of the respondents, $82.2 \%$, came from a family classified as poor, which has a monthly income of less than PHP 10,481. The data was from the Philippine Institute for Development Studies. 30 respondents were classified as a low-income class of those with a monthly income of between PHP 10,481 and PHP 20,962. 6 of the 213 respondents were lowermiddle-income, and two were classified under middle-income class. 


\section{Table 3}

\section{Number of Persons in the Household}

\begin{tabular}{ccc}
\hline Household Number & Frequency & Valid Percent \\
\hline 2 & 4 & 1.9 \\
3 & 15 & 7.0 \\
4 & 41 & 19.2 \\
5 & 55 & 25.8 \\
6 & 36 & 16.9 \\
7 & 28 & 13.1 \\
8 & 15 & 7.0 \\
9 & 10 & 4.7 \\
10 & 4 & 1.9 \\
11 & 3 & 1.4 \\
12 & 1 & .5 \\
14 & 1 & .5 \\
\hline Total & 213 & 100.0 \\
\hline
\end{tabular}

Table 3 shows that most of the respondents, which is $25.8 \%$, came from a family comprising of 5 members in the household. Nine respondents came from a family of greater than or equal to 10 . These are $4,3,1$, and 1 , respectively.

Table 4

Employment Status of Parents

\begin{tabular}{|c|c|c|}
\hline Employment Status & Frequency & Valid Percent \\
\hline Full Time & 32 & 15.0 \\
\hline Part Time & 35 & 16.4 \\
\hline Self Employed & 20 & 9.4 \\
\hline Unemployed due to COVID & 11 & 5.2 \\
\hline Not Working & 115 & 54.0 \\
\hline Total & 213 & 100.0 \\
\hline
\end{tabular}

The respondents were also asked about their parent's employment status, and the result showed that 115 of the respondents answered that their parents are not working or comprising more than half, which is $54 \%$ of the total respondents. This is because the school is situated in a rural area, so most of the respondents' parents depend on agriculture for a living. There were only 32 respondents with parent/s working full time while others are working part-time $(16.4 \%)$, self-employed $(9.4 \%)$, or unemployed because of the pandemic $(5.2 \%)$. 
Table 5

Descriptive Statistics of the Five Strands in Valencia National High School

\begin{tabular}{lccccc}
\hline Strands & $\mathrm{N}$ & Mean & Std. Deviation & $\begin{array}{c}\text { Minimum Score } \\
\text { Obtained }\end{array}$ & $\begin{array}{c}\text { Maximum } \\
\text { Score Obtained }\end{array}$ \\
\hline ABM & 23 & 18.17 & 6.436 & 6 & 30 \\
STEM & 30 & 15.97 & 3.489 & 6 & 22 \\
ATS & 52 & 10.67 & 5.360 & 1 & 24 \\
GA & 56 & 14.34 & 4.999 & 5 & 25 \\
EIM & 52 & 10.15 & 3.913 & 4 & 30 \\
\hline Total & 213 & 13.07 & 5.566 & 1 & 30 \\
\hline
\end{tabular}

Students under the academic tracks performed better in the summative test than those in the TVL tracks. The result showed that there is greater score gains from students in the academic track than students from the other tracks (Guill, Lüdtke, \& Köller, 2017).The highest mean, 18.17 with a standard deviation of 6.436 , came from the ABM strand, which means that among the five strands, ABM performed well in the General Mathematics summative test given by the researcher, followed by STEM with a mean of 15.97 and GA with a mean of 14.34. These three strands landed on the top three because these are academic strands, while ATS and EIM, both TVL strands, landed on the bottom two.

Students taking up TVL strands are more focused on hands-on activities, especially on their major subjects. Most of the students enrolled in this strand are working during the pandemic, making it difficult to juggle academics and work. They have less time to study than those belonging to the academic strands. This explains why the two strands landed low while the academic strands landed on the top three spots. ATS has a mean of 10.67 and a standard deviation of 5.360. EIM with a mean of 10.15 and a standard deviation of 3.913 performed the least among the five strands. With this result, teachers in General Mathematics, or even in other subjects, may exert extra effort in teaching the lessons to TVL students, especially under modular learning. Additional activities that will enable them to focus on learning the modules and engaging activities are highly encouraged.

Table 6

One Way Analysis of Variance on Students' Academic Achievement in General Mathematics

\begin{tabular}{cccccc}
\hline & Sum of Squares & df & Mean Square & F & Sig. \\
\hline Between Groups & 1682.044 & 4 & 420.511 & $17.905^{*}$ & .000000000001194 \\
Within Groups & 4885.036 & 208 & 23.486 & & 08 \\
\hline Total & 6567.080 & 212 & & \\
\hline${ }_{p}<0.001$ & & &
\end{tabular}

Table 6 shows the One-way Analysis of Variance (ANOVA) on the academic performance of the respondents in the different strata in General Mathematics. The result shows a significant difference in the academic performance of students under modular learning $\mathrm{F}(4,208)=17.905$, $p=0.000$. This is supported by a study that also revealed a significant difference in the 
proficiency level across SHS strands (Cerbito, 2020). A post hoc test using the Tukey HSD test was conducted to determine which strands show the significant result.

Table 7

Tukey HSD test on the Different Strands

\begin{tabular}{cccc}
\hline \multirow{2}{*}{ (I) Strand } & (J) Strand & Mean Difference (I-J) & Sig. \\
\hline \multirow{3}{*}{ ABM } & STEM & 2.207 & .472 \\
& ATS & $7.501^{*}$ & .0000000331 \\
& GA & $3.835^{*}$ & .014 \\
& EIM & $8.020^{*}$ & .000 \\
ABM & -2.207 & .472 \\
STEM & ATS & $5.294^{*}$ & .0000347807 \\
& GA & 1.627 & .574 \\
& EIM & $5.813^{*}$ & .000 \\
& ABM & $-7.501^{*}$ & .000 \\
STEM & $-5.294^{*}$ & .000 \\
& GA & $-3.666^{*}$ & .001 \\
& EIM & .519 & .982 \\
& ABM & $-3.835^{*}$ & .014 \\
& STEM & -1.627 & .574 \\
GA & ATS & $3.666^{*}$ & .001 \\
& EIM & $4.185^{*}$ & .000 \\
& ABM & $-8.020^{*}$ & .000 \\
& STEM & $-5.813^{*}$ & .000 \\
& ATS & -.519 & .982 \\
EIM & GA & $-4.185^{*}$ & .000 \\
\hline
\end{tabular}

*.The mean difference is significant at the 0.05 level.

Results in Table 7 revealed that ABM showed a significant difference to ATS, GA, and EIM. STEM significantly differs from ATS and EIM. ATS showed a significant difference with GA, and GA showed a significant difference with EIM. Mamolo (2019) revealed that the strands under the academic track are more focused on the academe, while strands under the TVL track focus more on skills development. Meanwhile, ABM showed no significant difference with STEM, STEM showed no significant difference with GA, and ATS showed no significant difference with EIM. This means that respondents under the ABM strand scored significantly higher among the five strands than the others. Specifically, ABM performed well in the test compared to the different strands. Since ABM students are also exposed to mathematical practices concerning their strand, students have developed mathematical skills making them more knowledgeable on the topics. ABM strand offers other branches of Mathematics, including those major subjects intended just for their strand, e.g., Fundamentals of ABM. These major subjects helped them develop their mathematical skills making them performed best among the other strands. Most students enrolled in this strand are also girls. Female senior high 
school students tend to have more favorable study habits than males (Casinillo, Batidor, May, \& Casinillo, 2020). This is supported by Almerino et al. (2020) who found that ABM outperformed STEM in terms of mathematical application despite their exposure to problem solving and other mathematical applications.

Table 8

Pearson Correlation Result on Demographic Profile of Grade 11 Students and Score in General Mathematics

\begin{tabular}{lcccccc}
\hline & & Sex & Income & Household & Employment & Score \\
\hline Sex & Pearson Correlation & 1 & $.422^{* *}$ & $.530^{* *}$ & $.580^{* *}$ & $-.330^{* *}$ \\
Income & Sig. (2-tailed) & & .000 & .000 & .000 & .000 \\
& Pearson Correlation & $.422^{* *}$ & 1 & $.751^{* *}$ & $.352^{* *}$ & $.142^{*}$ \\
Household & Sig. (2-tailed) & .000 & & .000 & .000 & .039 \\
& Pearson Correlation & $.530^{* *}$ & $.751^{* *}$ & 1 & $.752^{* *}$ & -.001 \\
Employment & Sig. (2-tailed) & .000 & .000 & & .000 & .991 \\
& Pearson Correlation & $.580^{* *}$ & $.352^{* *}$ & $.752^{* *}$ & 1 & $-.147^{*}$ \\
& Sig. (2-tailed) & .000 & .000 & .000 & & .032 \\
\hline$* *$ Correlation is significant at the 0.01 level (2-tailed). & $* 13<0.001$ & & 213 \\
$*$ *. Correlation is significant at the 0.05 level (2-tailed). & & &
\end{tabular}

Table 8 presents the correlation result of the demographic profile of the respondents and the scores in General Mathematics. The result showed a correlation between sex, income, and employment to the score of the respondents. There is a significant, moderately, and negative correlation between sex and score $(\mathrm{r}=-0.330, p<0.001)$. Further, there is a significant, low, and negative correlation between the employment status of parents and score $(\mathrm{r}=-0.147, p=0.032)$. This indicates that as parents are working on a full-time basis, time spent on the student will lessen, thus decreasing academic performance. There is little time for parent participation since most of the time will be spent on work. There is a difficulty in monitoring the status of their child's submission of modules due to heavy workload. Working parents lack the time to guide their child than stay-at-home parents, especially mothers as housewives (Carbonel, Banggawan, \& Agbisit, 2013). Dumont et al. (2012) supports this by claiming that students' academic performance is affected by the level of parental involvement. However, there is a significant, low, and positive correlation between income and academic performance $(r=0.142$, $p=0.039$ ). Parents' low income means difficulty providing a conducive environment for studying, gadgets used such as cellphone or computers, and other supplementary materials. Higher parents' income also attributes to parents who are more capable of teaching their children. Students whose parents earn higher income graduated from college and landed a stable job, thus have higher salaries. With this, they totally have the capacity to tutor their child or hire one increasing their academic performance. Farooq et.al. (2011) strengthens this result that socioeconomic status affects the overall performance of a student in Mathematics. The result of this study will imply the need for parents to provide adequate support in their child's schooling. The government must also help alleviate the gap between the high and the low socialeconomic status by providing financial assistance to the less privileged, opening a job fair, or offering scholarship grants to deserving students. Meanwhile, there is no significant correlation 
between the numbers of persons in the household and the score in General Mathematics $(\mathrm{r}=$ 0.001, $p=0.991)$. It can also be seen from the data presented that sex and income has a significant, moderate, and positive correlation $(\mathrm{r}=0.422, \mathrm{p}<0.001)$. This means that higher income correlates to a particular sex.

Table 9

z-Test for the Academic Performance of Grade 11 Students based on Sex

\begin{tabular}{lcc}
\hline & Female & Male \\
\hline Mean & 14.88785047 & 11.22641509 \\
Known Variance & 29.81749251 & 25.64348607 \\
Observations & 107 & 106 \\
z & $5.074629801^{*}$ & \\
z Critical two-tail & 1.959963985 & \\
\hline
\end{tabular}

*.The mean difference is significant at the 0.05 level.

Table 9 reveals the result or statistical difference between males and females. The result shows a mean of approximately 14.89 for females with a variance of 29. 82. Meanwhile, a mean of 11.23 was computed for males and a variance of 25. 64. This means that the female significantly scored higher than the male. The value of $\mathrm{z}$ is 5.07 at a $5 \%$ significance level and is greater than $\mathrm{z}$ critical, which is approximately 1.96 . With this, there is a significant difference in male and female academic performance in modular learning. $\mathrm{Z}$ test for two means showed that females performed better than males. Females are more conscious about their school performance, and they tend to compete with their other classmates. Female students are more emotional than males, which means that they are easily affected by increased or decreased scores. Al-Mutairi (2011) supports this claim that female achievement in academics is higher than male. Female senior high school students tend to have more favorable study habits than males (Casinillo, Batidor, May, \& Casinillo, 2020). It was also found out by Ganley \& Lubienski (2016) that girls value mathematics achievement more than boys. Casinillo et al. (2020) further stated that females tend to be more anxious than males in studying Mathematics. Contrary to this, Goetz et al. (2013) demonstrated that girls performance in Mathematics is not affected negatively despite their higher level of anxiety. With this result, the gender gap will lessen. Thus, mathematics intervention should start at an early age to eliminate anxiety or other factors intertwined with sex affecting academic performance in Mathematics.

Test of validity was done using Pearson Product Moment Correlations using SPSS. Item is valid if $r_{\text {value (item) }}>r_{\text {table }}$. Result revealed that at alpha 0.05 , there is only one item invalid, that is, item number 1 . There are 29 items valid, and these items are items 2-30. In this study, Cronbach's alpha was used to evaluate the internal consistency of the instrument, which is the most common validation as presented in the literature (Paiva, et al., 2014). The result showed the reliability of the 30-item questionnaire administered to the respondents is 0.792 . Based on descriptors provided by Taber (2016), reliability of 0.792 is classified as fairly high. This means that the questionnaire will yield a high probability of a consistent result. The researcher used the Kolmogorov-Smirnov test to determine whether the distribution of data is normal or not. For the normality test, if the significance level is greater than 0.05 , the distribution is normal. Based on the test conducted to the data, the significant value of the test scores is 0.102 and for 
the strands is 0.188 . Thus, both data were normally distributed. A test of equality of variances was conducted using Levene's test to determine the homogeneity of variances. If the p-value is above 0.05 , equality of variance is assumed - otherwise, violation of the assumption. The result verified the equality of variances with a p-value of 0.631 , which is greater than the alpha 0.05 , concluding equality among the group variances.

\section{Conclusion}

This study showed that the Accounting, Business and Management Strand (ABM) performed the best under the modular learning approach among the senior high school strands of Valencia National High School (ABM). This was because most students in this strand are girls, and based on the result above, sex and score correlate with one another. Evident in the results presented, among the five strands, those belonging to the academic track, namely ABM, STEM, and GA, performed better than EIM and ATS strands, which fall under the TVL track. This result shows the need to promote the TVL track in terms of their academy while focusing on developing their skills. Teachers designated to teach in this track must exert extra effort in using their teaching methods and strategies, especially in this time of current shift in the educational system.

Results also showed that females performed better in modular learning than males. This result eliminates the gender gap between the male and the female, erasing the notion that males perform better in mathematics than females. On the other hand, the majority of the respondents' parents are not working. Thus, there is less or no income at all, decreasing students' scores in the summative test. Parents are not capable of teaching nor have the financial capability to provide for their child's needs. With these, modular learning is effective for students with a strong foundation in mathematics and the essential learning tools that aid the understanding of lessons. The researcher would like to extend the study by focusing on male and female academic performance in each strand. The correlation test among the demographic profile of the respondents and their academic performance in each strand is also a favorable study to conduct. Further, the significant and positive correlation shown between sex and income is also an excellent study to perform in the future.

\section{Acknowledgement}

I would like to extend my gratitude to the student respondents as well as to their parents for their effort in the participation of this study. This would also not be possible without the approval of our school head and head teacher to conduct the study at Valencia National High School. I would also like to extend my gratitude to my family for the constant care and support you have given me (financially, emotionally, physically, or mentally) throughout this research journey. This would not be possible without your words of encouragement. 


\section{References}

Al-Mutairi, A. (2011). Factors affecting business students' performance in arab open university: The case of kuwait. The International Journal of Business and Management, 6(5), 146-155.

Almerino, P. M., Ocampo, L. A., Abellana, D. P. M., Almerino, J. G. F., Mamites, I. O., Pinili, L. C., Tenerife, J. J. L., Sitoy, R. E., Abelgas, L. J., \& Peteros, E. D. (2020). Evaluating the academic performance of K-12 students in the philippines: A standardized evaluation approach. Education Research International. https://doi.org/10.1155/2020/8877712

Carbonel, L. G., Banggawan, M. L., \& Agbisit, I. (2013). Parents' role in enhancing he academic performance of studentsin the study of mathematics in tabuk city, philippines. International Journal of Advanced Research in Management and Social Sciences, 2(8), 302-317. Retrieved from www.garph.co.uk.

Casinillo, L. F., Palen, M. A. E., Casinillo, E. L., \& Batidor, P. G. (2020). Assessing senior high student's learning experiences in mathematics. Indonesian Journal of Educational Studies, 23(1), 44-60. https://doi.org/10.26858/ijes.v23i1.13437

Cerbito, A. F. (2020). Comparative analysis of mathematics proficiency and attitudes toward mathematics of senior high school student. International Journal of Scientific and $\begin{array}{llll}\text { Research } & \text { Publications } & \text { (IJSRP), } & \text { 10(5), }\end{array}$ http://dx.doi.org/10.29322/IJSRP.10.05.2020.p10125

DepEd. (2019) PISA 2018 National Report of the Philippines. The Philippines Department of Education. $\quad$ https://www.deped.gov.ph/wp-content/uploads/2019/12/PISA-2018Philippine-National-Report.pdf.

Dumont, H., Trautwein, U., Ludtke, O., Newmann, M., Niggli, A., \& Schnyder, I. (2012). Does parental homework involvement mediate the relationship between family background and educational outcomes? Contemporary Educational Psychology, 37(1), 55-69.

Farooq, M. S., Chaudhry, A. H., Shafiq, M., \& Berhanu, G (2011). Factors affecting studentse quality of academic performance: a case of secondary school level. Journal of Quality and Technology Management, 7(2), 1-14.

Ganley, C. M., \& Lubienski, S. T. (2016). Mathematics confidence, interest, and performance: Examining gender patterns and reciprocal relations. Learning and Individual Differences, 47, 182-193. https://doi.org/10.1016/j.lindif.2016.01.002

Goetz, T., Bieg, M., Lüdtke , O., Pekrun , R., \& Hall, N. C. (2013). Do girls really experience more anxiety in mathematics? Psychological Science, 24(10), 2079-2087. https://doi.org/10.1177\%2F0956797613486989

Guill, K., Lüdtke, O., \& Köller, O. (2017). Academic tracking is related to gains in students' intelligence over four years: Evidence from a propensity score matching study. Learning and Instruction, 47, 43-52. 
Mamolo, L. (2019). Analysis of senior high school students' competency in general mathematics. Universal Journal of Educational Research, 7(9), 1938-1944. doi: https://doi.org/10.13189/ujer.2019.070913

Manlangit P, A. M. (2020). Supercharging filipino parents is key for successful modular distance learning. FlipScience.

Paiva, P. C. P., de Paiva, H. N., Oliveira Filho, P. M. D., Lamounier, J. A., Ferreira, E. F. E., Ferreira, R. C., Kawachi, I., \& Zarzar, P. M. (2014). Development and validation of a social capital questionnaire for adolescent students (SCQ-AS). PLoS ONE, 9(8), e103785. https://doi.org/10.1371/journal.pone.0103785

Taber, K S. (2016). The use of cronbach's alpha when developing and reporting research instruments in science education. Research in Science Education, 48(6), 1273-1296. https://doi.org/10.1007/s11165-016-9602-2 
Comparison on the Effectiveness of Modular Learning in General Mathematics among the Senior High School Strands 